\title{
Malditos vs marginais?
}

\author{
Michel Riaudel
}

Resumo: No jornal O Beijo (Rio de Janeiro, 1977), Ana Cristina Cesar publicava um texto chamado "Malditos marginais hereges". Nele, a poetisa reagia a uma coletânea de contos organizada por João Antônio, lançada no mesmo ano, e reunidos sob o título Malditos escritores!. Nossa proposta é examinar os termos desta polêmica levando em conta o contexto (ditadura, poesia marginal...) e repensar as categorias de maldito e/ou marginal aplicadas no âmbito da cultura e da literatura.

Palavras-chave: Ana Cristina Cesar; João Antônio; poesia marginal; contracultura

Résumé: Dans le journal O Beijo (Rio de Janeiro, 1977), Ana Cristina Cesar a publié un texte intitulé "Maudits marginaux hérétiques". Elle y réagissait à la publication de nouvelles réunies par João Antônio et parues cette même année sous le titre Maudits écrivains!. Notre intention est d'examiner les termes de cette polémique, en tenant compte de son contexte (dictature, essor de la poésie marginale...), et d'éprouver ces catégories de maudits ou de marginaux pour penser le lieu de la culture et de la littérature en particulier.

\footnotetext{
Abstract: In the newspaper "O Beijo" ("The Kiss" -- Rio de Janeiro, 1977), Ana Cristina Cesar published a text titled "Malditos marginais hereges" (Damned heretical marginals.) In it, the poet reacted to a collection of stories organized by João Antonio, released in that same year under the title "Damned writers." Our proposition is to examine the terms of that argument, taking into account the context (dictatorship, marginal poetry...), and to rethink the categories of damned and/or marginal, applied to the scope of culture and literature.
}

Keywords: Ana Cristina Cesar; João Antônio; marginal poetry; counterculture 
Em março de 1977, o número 4 da revista de São Paulo Extra publicou um dossiê organizado por João Antônio e intitulado "Malditos escritores". Reunia nove contos inéditos de nove autores diferentes: Chico Buarque, Antônio Torres, Wander Piroli, Marcos Rey, Márcio Souza, Aguinaldo Silva, Tânia Faillace, Plínio Marcos e o próprio João Antônio.

A capa estampava os nove retratos 3x4, e mais uma décima foto exibindo o ilustrador Elifas Andreato, muito solicitado na época, todos com indicação de data no canto inferior do busto como se tivessem sido fichados pela polícia. O que em contexto de ditadura sugeria muito da coragem desses escritores, desafiando a censura e a repressão.

O recado era reforçado pelo forte contraste em preto e branco, sem nuances possíveis, em que se destacam as letras garrafais do título: "malditos escritores", com ponto de exclamação. Um texto na coluna direita deixava mais clara ainda a provocação:

Eles não se emendam: sempre falando no miserê geral, no desemprego e no emprego da força; no feijão, na carne dos amantes, futebol, homossexualismo, cadeia; sempre falando no coração, fígado e intestinos da realidade brasileira. Raça maldita.

Eles, quem? Os selecionados da antologia. Mas então quem está falando? Quem seria esta primeira pessoa, qualificando e decretando todos eles malditos? Os responsáveis da revista Extra? Deixemos por enquanto a pergunta sem resposta definitiva, em suspenso.

Na contracapa, umas palavras de João Antônio desenvolviam a chamada, opondo de um lado o mundo dos doutores, da cartolagem, dos sabidos, e de outro o exército dos humilhados, explorados, oprimidos, discriminados lá de baixo, prostitutas, mendigos, policiais, praças... "cujos gritos não chegam ao conhecimento geral e a conhecimento nenhum". Essas frases, por sua vez, são apenas a conclusão do texto maior de apresentação, texto-manifesto, "O buraco é mais embaixo", que se abre com a constatação de que "O povo parece haver tomado chá de sumiço das letras nacionais".

[...] por isso mesmo, aqui se tentou - sem aflições estéticas ou existenciais, sem dar bandeiras ou distribuir mesuras à crítica elitista - levantar um conjunto de trabalhos que ao menos tentasse, com alguma limpeza e objetividade, refletir e repensar realidades brasileiras em um leque geográfico variado, a expor em nível acessível um punhado de histórias das classes subalternas. 


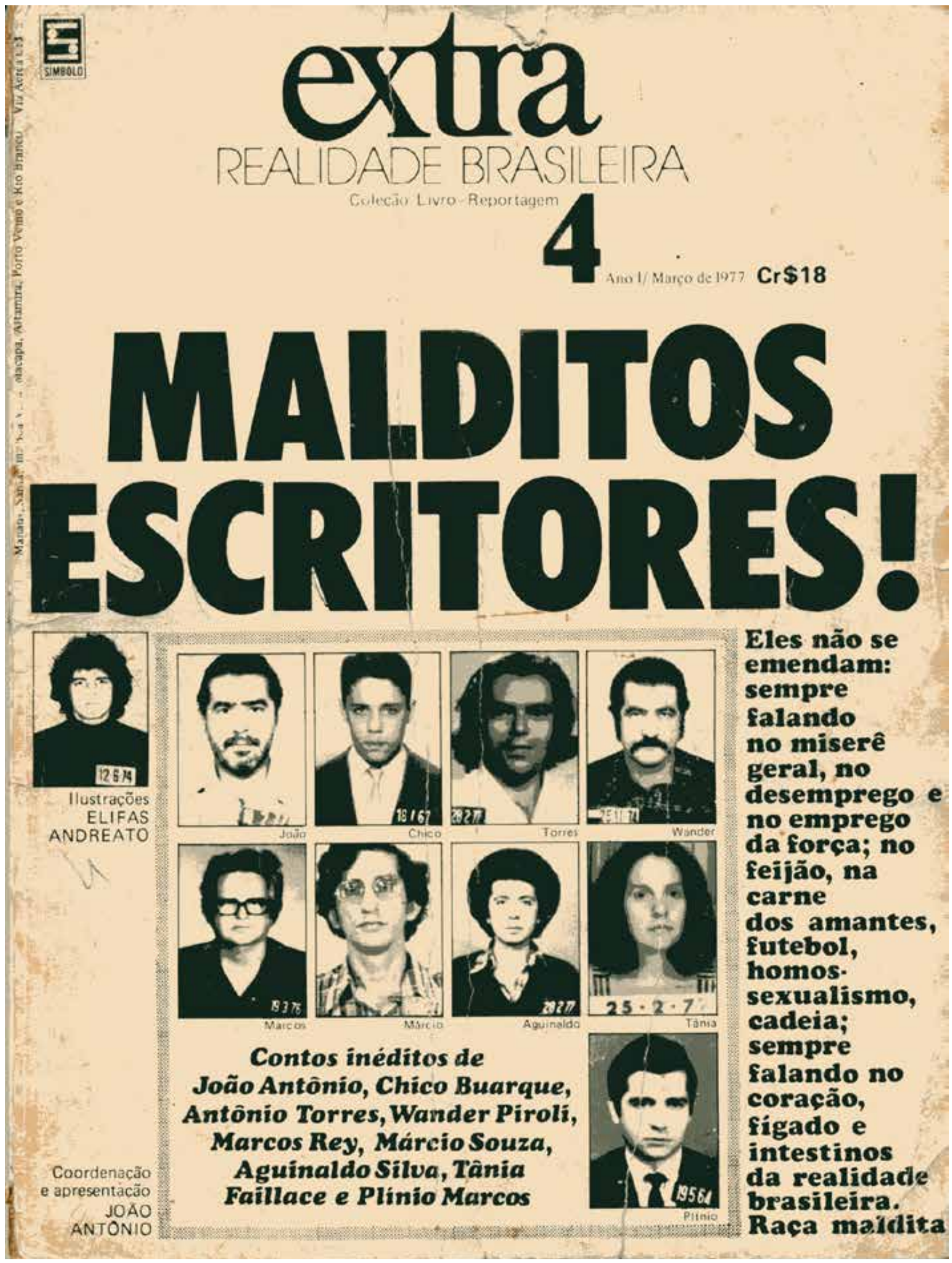


A narrativa, diz ainda o prefácio, "evitou o toque beletrístico", se comprometeu "com a coisa claramente popular", tendendo a se identificar com o objeto retratado: uma literatura "antropológica", de uma antropologia participativa em que o observando se parece e é solidário do observado. Nesta recusa do "estético por si só", cometem-se "quase todas as heresias diante de alguns conceitos tradicionais do purismo do fazer literário". Trata-se de um "corpo-a-corpo com a vida", de uma "literatura fedida", adequada ao "mundo fedido" dos humildes.

Mas a chamada da capa só passa a adquirir pleno sentido quando se lê a epígrafe de Castro Alves, na folha de rosto:

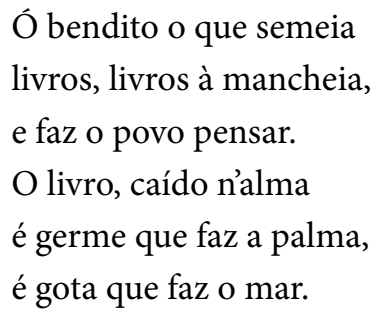

São versos extraídos do último volume publicado pelo poeta baiano enquanto vivo, Espumas flutuantes, em 1870, isto é, um ano antes de sua morte. "O livro e a América", aliás o texto de abertura da coletânea, ressalta a importância da literatura e da leitura para a formação do povo (para não dizer do cidadão) americano.

Oito meses depois do lançamento desse número da Extra, já em novembro de 1977, a primeira edição do jornal carioca O Beijo publica, em reação, um ensaio assinado por Ana Cristina Cesar: "Malditos marginais hereges".' Seguindo o procedimento da parataxe do título, justapondo três categorias de gente que está de mal com as leis sociais, a poetisa aponta as diversas discrepâncias do discurso maldito. Uma das primeiras contradições denuncia a estratégia comercial:

Os adjetivos de maldição e marginalidade, os retratinhos e as feias broncas não foram às bancas para atrair repressão. Mas para embalar ideologicamente o produto a ser vendido. [... A embalagem] acondiciona e garante a circulação do produto, a sua receptividade

1. In: CESAR, Ana Cristina. Escritos no Rio, Armando Freitas Filho (Org.). São Paulo: Brasiliense; Rio de Janeiro: UfRJ, 1993, pp. 109-119. 
numa fatia do mercado. A embalagem altera e integra o significado da produção. Fica montada, antes mesmo da leitura, uma cumplicidade especial com certo leitor, com base na heroização dos escritores e no aproveitamento de uma atual simpatia automática - ou desesperada - por qualquer que "proteste". Simpatia por qualquer produto "perseguido" - mesmo que este venda 25 mil exemplares com espantosa rapidez. ${ }^{2}$

Estaríamos diante da tradição de certa linha de manifestos, polêmica, retórica e escandalosa, arguindo da posição do fraco contra o forte em tom convencionalmente agressivo e paranoico, construindo e encenando uma situação de vítima, valendo-se das perseguições dos outros para atrair para seu próprio caso a piedade do leitor. Ana Cristina mobiliza o vocabulário do marketing para reforçar a demonstração (produto, mercado, embalagem, as cifras de venda, a popularidade dos pontos de divulgação: a banca...), mas insiste sobretudo em duas outras vertentes da contradição: o verdadeiro estatuto do escritor em jogo, a concepção do leitor, ambos tendo como sustento ideológico a estética mimética.

Na contraposição do "malditos" da capa e do "bendito" do verso de Castro Alves, aparece com mais nitidez a lógica do discurso: "Eles" são tidos por malditos pelos dominantes, quando são na verdade os "benditos". Sendo que o "eu" enunciando este "eles" explícito, indiciado, é ventríloquo. Decorre de discurso forjado pelos organizadores da antologia e atribuído a outros "eles" implícitos, os donos do poder, no intuito de estabelecer uma cumplicidade entre a segunda pessoa, o leitor, e o eu, autor, assim reunidos para constituir uma nova categoria de "nós", juntos na resistência e no protesto. A primeira pessoa (velada) da capa falava em nome da ideologia, dos potentes, supostamente ameaçados por esta literatura "participativa". Aliás, como concluía João Antônio,

Literatura? Mas, minha querida senhora, a literatura não existe. O que há é a vida, de que a política e arte participam.

Bem se sabe que não há argumento racional capaz de desmontar a retórica da paranoia, pois esse sempre seria suscetível de ser considerado como uma prova a mais da efetividade da perseguição. No entanto, Ana Cristina Cesar avança dois elementos sustentando sua crítica. O primeiro deles é a dupla qualificação do escritor, na Extra, ao mesmo tempo assimilado ao povo, sofrendo da exploração, dividindo com ele o "miserê", e pai

2. Id., pp. 112-113. 
do povo, com seus livros fazendo-o pensar. Notemos en passant a reescrita do verso de Castro Alves, no original: "Oh! Bendito o que semeia/ Livros... livros à mão cheia.../ E manda o povo pensar!”. Percebe-se um deslize significativo no lapso da citação, já que no verso de Castro Alves o poeta incentiva e/ou ordena, mas não se substitui ao exercício do pensamento, enquanto na epígrafe da Extra, ao fazer pensar o povo, o poeta ou o escritor acaba pensando no lugar dele. Mas, no fundo, o que importa é que assim o autor se vê incumbido de uma tarefa, tornando-se um missionário, um semeador, a plantar os germes da emancipação no campo virgem, quando não alienado, da consciência popular.

A crítica de Ana Cristina Cesar faz-se então mais explícita:

[...] falta consciência de classe ao intelectual, que se acredita mais uma vez porta-voz dos oprimidos, setor transparente que reflete as imagens e os gritos ocultos dos banguelas e desbocados. Essa falta é socialmente favorecida. Historicamente motivada. É bom que o intelectual desconheça a sua função de controle e de reprodução social, e que não leve a contestação ao nível concreto da sua prática. Jornalistas, professores, advogados, cientistas - não fiquemos só nos técnicos e burocratas. A Informação, a Educação, o Direito, a Ciência, mitos que ainda acalentamos, mesmo se coloridos com a Discórdia. ${ }^{3}$

Reconhecemos o vocabulário foucaultiano pelo qual a poetisa vem condenando a onipotência do narrador realista, a prepotência da estética naturalista. Três anos mais tarde, em Luvas de pelica, segue tematizando essas discussões:

Imagino a onipotência dos fotógrafos escrutinando por trás do visor, invisíveis como Deus. $^{4}$

[...] Estou jogando na caixa do correio mais uma carta para você que só me escreve alusões, elidindo fatos e fatos. É irritante ao extremo, eu quero saber qual foi o filme, onde foi, com quem foi. É quase indecente essa tarefa de elisão, ainda mais para mim, para mim! É um abandono quase grave, e barato. Você precisava de uma injeção de neorrealismo, na veia. ${ }^{5}$

3. Id., pp. 114-115.

4. CESAR, Ana Cristina. A teus pés. São Paulo: Brasiliense, 1982, p. 96.

5. Id., p. 102. 


\section{[...] Discutimos o veio masoquista com olho bem naturalista. ${ }^{6}$}

A escrita de Ana Cristina Cesar é de fato toda feita de opacidade, reflexos, emaranhando subjetividades alusivas, elípticas. Ao contrário desse número da Extra, cujo título completo é Extra Realidade Brasileira, Coleção Livro-Reportagem e que oferece uma escrita redundante, da insistência, em que os recados são repetidos $n$ vezes. A linha realista no fundo não está preocupada com a realidade, mas, sim, com a verdade. Essa nuance aparece claramente na citação de uma entrevista concedida por João Antônio e citada em "Malditos marginais hereges":

Os escritores estão muito elitizados, não é? O escritor em geral tem medo de ir pra um campo de futebol, ir pra geral e tirar a camisa porque tá quente. Se coloca numa posição de intelectual olhando as coisas por cima. Em geral é muito dono da verdade, não gosta de andar de ônibus, andar de trem, gosta muito de emprego público, de mecenato...

O escritor brasileiro é um indivíduo que foge de qualquer tipo de realidade que não seja uma realidade agradável, componente de um bom comportamento; o escritor brasileiro é um homem que se coloca muito na classe média, e a classe média vive mais de mentiras, vive de consumos... (João Antônio, em entrevista ao jornal Ex).?

Ou seja, a realidade "agradável" está associada à mentira. Sendo que o escritor elitizado vira as costas para a outra realidade, mais verdadeira (ou, melhor dizendo, a única a ser verdadeira), desconfortável, do campo de futebol, do ônibus, do trem... E mesmo assim ele é "dono da verdade". A tradução positiva dessa declaração de João Antônio leva o escritor a imergir na vida desagradável do povo, na prática, na linguagem, para revelar a legítima realidade. Ele é quem faz desabar as miragens de classe, as ilusões, para finalmente expor em palavras cruas e incômodas, sem disfarce, sem “-ismo", sem estética, a verdade. Sua relação com o real é bem diferente daquela do pintor da vida moderna, na leitura de Baudelaire redefinida por Foucault:

[...] na hora em que o mundo todo entra no sono, ele [o pintor moderno] põe-se a trabalhar e transfigura-o, transfiguração que não é cancelamento do real, mas jogo difícil

6. Id., p. 106.

7. Escritos no Rio, op. cit., pp. 118-119. 
entre a verdade do real e o exercício da liberdade [...]. A modernidade baudelairiana é um exercício em que a extrema atenção para o real se defronta com a prática de uma liberdade que ao mesmo tempo respeita esse real e o violenta. ${ }^{8}$

Nas palavras de Michel Foucault, a tarefa do artista não seria apenas dar conta do real, mas transfigurá-lo, numa operação de "translação" nos vários sentidos que a palavra translation tem em inglês. Importa ao artista moderno o estupro do real, o exercício de sua liberdade criativa e histórica. Mesmo não conhecendo esse texto de Foucault, de alguns anos posterior à nossa polêmica, Ana Cristina Cesar também convida, não diretamente a mandar pensar (ou fazer pensar) o povo, mas a repensar revolucionariamente o trabalho do intelectual:

O intelectual de esquerda ainda é o sujeito que tem ideias, opiniões, inclinações revolucionárias, mas que não consegue repensar revolucionariamente o próprio trabalho: sua relação com os meios de produção intelectual, sua técnica, seu poder de dizer. ${ }^{9}$

Nessa perspectiva antipopulista, não se trata apenas de assumir um ponto de vista, de saber a impossibilidade da objetividade, nem de se entregar meramente a uma autocrítica implacavelmente solipsista, trata-se da consciência dos limites da literatura. Do lado "maldito", manifesta-se uma adesão, uma crença (experta ou ingênua - provavelmente mais ingênua do que experta no caso de João Antônio) nos poderes do autor. À pergunta "O que pode a literatura?", o realista maldito responde otimistamente, euforicamente, de forma interesseira, calculadora ou abnegada, militante, que pode muito ou pode tudo. Vale tudo.

Ana Cristina Cesar tem, pelo contrário, plena lucidez (valeriana) de que os poderes do autor já estão limitados pelos poderes do leitor, não mais receptor ou consumidor passivo, mas em que reside a última palavra (provisória) do sentido do texto. Segundo ela, já não é possível achar, assim como Castro Alves ou os benditos malditos,

8. "[...] à l'heure où le monde entier entre en sommeil, il se met, lui [le peintre moderne], au travail, et il le transfigure. Transfiguration qui nesst pas annulation du réel, mais jeu difficile entre la vérité $d u$ réel et lexercice de la liberté [...]. La modernité baudelairienne est un exercice où lextrême attention au réel est confrontée à la pratique d'une liberté qui tout à la fois respecte ce réel et le viole.» Michel Foucault, "Qu'est-ce que les lumières?", in: Dits et Écrits II, Paris: Gallimard, coll. "Quarto", 2001, p. 1389 ["What is Enligthenment?", in: Rabinow (P.), éd., The Foucault Reader. Nova York: Pantheon Books, 1984].

9. Escritos no Rio, op. cit., p. 115. 
que o intelectual ou o artista pode modelar o cérebro, decidir da conformação e das orientações do espírito de seu público. Aliás, essa possibilidade nem iria de acordo com o exercício da democracia, da cidadania. Por isso, o que deve nortear a escrita, a poesia, é de certa forma uma posição cética, sendo que "A desconfiança não é só um jogo do contra". ${ }^{10}$

Talvez se possa acreditar que ela escreve tendo em mente, na contramão da maldição, a marginalidade então em voga e à qual ela parece ter se filiado. No ano anterior, no dia 15 de junho de 1976 tinha sido lançada com muita repercussão a antologia organizada por Heloisa Buarque de Hollanda, 26 poetas hoje, ${ }^{11}$ da qual Ana Cristina Cesar fazia parte. O volume consagra o reconhecimento de uma "poesia marginal" nascida no início da década, na virada de 1971 para 1972, com dois livrinhos autoeditados: Travessa Bertalha 11, de Charles, e Muito prazer, Ricardo, de Chacal. Na esteira dessa afirmação de uma nova geração de poetas, em março de 1977, isto é, concomitantemente com a publicação do número da Extra, cogita-se no Rio de Janeiro o lançamento de um jornal alternativo. Constitui-se então um grupo que passa a se reunir com frequência, e que Ana Cristina Cesar integra logo no começo do mês de abril. Nas palavras de outro participante, Marcos Augusto Gonçalves:

O grupo, grande e bastante heterogêneo, tinha em comum o sentimento de inadaptação à cultura hegemônica de oposição ao regime militar, ainda bastante influenciada pelo ideário do Partido Comunista, nacionalista, conteudista e populista. Queríamos discutir sexo, feminismo, falar de Foucault, poder criticar abertamente a União Soviética, a herança cultural do CPC, a estreiteza da militância e a própria imprensa. ${ }^{12}$

Lendo as lembranças de Marcos Augusto Gonçalves, numa Folha Ilustrada de 13 de dezembro de 1997, tudo constrói a oposição entre o grupo dos realistas malditos, conteudista, populista, e o grupo carioca marginal. Enquanto o maldito assumiria uma posição absoluta, guerreando contra o establishment, profanando a norma elevada a partir de um lugar antagônico, chulo, baixo, o marginal brincaria num espaço mediano, de fronteiras indefinidas, nem centro, nem periferia. A margem do caderno, da folha,

10. Id., p. 115.

11. HOllanda, Heloisa Buarque de (Org.). 26 poetas hoje. Rio de Janeiro: Labor, 1976.

12. Folha Ilustrada, São Paulo, 13 de dezembro de 1997. 
ainda faz parte da página, é um lugar relativo, certamente afastado do centro, mas capaz de se tornar centro em relação à outra margem. O maldito assumiria seriamente a função prometeica de desafiar os deuses e promover os homens, de os igualar aos moradores do Olímpio pelo roubo sacrilégio; o marginal parecer-se-ia com o desastrado irmão Epimeteu, aquele que reflete après-coup, depois de ter agido e provocado catástrofes, figura cômica e antecipadora do trickster, palhaço que participa dos dois mundos ao mesmo tempo para melhor subvertê-los no curto-circuito do riso e do deboche.

Mas lendo com mais cuidado a contribuição de Ana Cristina Cesar no Beijo, nota-se que na realidade ela não opõe marginais a malditos. Pelo contrário, assimila -os, como o ilustram vários trechos do texto:

Desde a capa, os escritores são adjetivados com garrafal MALDitos que lhes anuncia o status marginal (p. 112).

Os adjetivos de maldição e marginalidade (p. 112).

Se é pra fazer literatura "maldita" ou "marginal", não há que desafiar as normas reais ou sentimentais dominantes que catalogam os sujeitos merecedores da nossa PENA? Ou pelo menos não disfarçar que também nos rebolamos de piedade por nós mesmos, que somos outros, e não iguais, em relação à chamada "gente humilde"? (pp. 118-119).

A distância que vai de umas a outras é a distância (não moralizável) da mediação literária e a distância (indisfarçável, apesar da nossa culpa) entre produtores/leitores de literatura - Escritores Malditos, Poetas Marginais, Jorge Amado, Beijo, ou o que for - e as "massas populares" (p. 119).

Em todas essas ocorrências, maldito e marginal equivalem-se. Vale lembrar que nos meados dos anos 70 o rótulo de poesia marginal não faz então consenso entre os próprios poetas. Heloísa Buarque de Hollanda, no posfácio que ela inclui na reedição comemorativa de 26 poetas hoje, em 1998, fala em:

fenômeno que, na época, foi batizado com o nome poesia marginal, sob protestos de uns e aplausos de outros. ${ }^{13}$

13. Hollanda, Heloísa Buarque de. Posfácio à reedição de 26 poetas hoje. Rio de Janeiro: Aeropla- 
Alguns recusam o qualificativo, lendo nele um sinal de desprezo, outros o reivindicam pelo mesmo motivo, assim como Hélio Oiticica adotava como slogan "Seja herói, seja marginal”. Na verdade, ela saiu do projeto editorial poucas semanas antes do lançamento do número 1, em novembro, que publica, contudo, o seu texto sobre ou contra a orientação do número da Extra. "Esse meu trabalho sobre Malditos Escritores é sobre um certo engajamento", escreve ela a Maria Cecília Fonseca em julho deste mesmo ano. ${ }^{14}$ Engajamento que pode visar, como o vimos, "Escritores Malditos, Poetas Marginais, Jorge Amado, Beijo, ou o que for".

Quem frequenta a sua poesia bem sabe que ela é mestre em jogo de sinuca, bate numa bola para atingir e mover outras. Cada palavra tem sua superfície e suas significações soterradas, ocultas, diversas; diz várias coisas ao mesmo tempo, embutindo um discurso em outro, uma citação na outra. Não é nada improvável que este ensaio aparentemente contra os "malditos" tenha destinatário interno ao próprio Beijo, desde a fase de projeto atravessado por tensões entre a influência do "articuladíssimo" Escobar e a linha mais libertária de Júlio César Montenegro. ${ }^{15}$ Ler-se-ia então seu texto como carta explicativa da demissão de Ana Cristina antes mesmo de o jornal vir à luz.

Mas, para além das leituras circunstanciais, entendemos que a causa da discussão é de âmbito maior e diz respeito ao lugar do escritor e da literatura hoje. A postura "maldita" ou certa postura marginal - Ana Cristina distinguia o marginal de opção política, coletiva, e o marginal de circunstância ou oportunismo - sonha com e reconstitui um lugar do sagrado, num mundo que de sagrado não tem mais nada. Ele fica reinventando valores absolutos, limites intransponíveis, tabus a serem transgredidos numa economia empenhada a digerir e integrar em termos mercadológicos todas as revoltas, incluindo as mais radicais. No texto já citado de Foucault, em que ele se volta não só para o texto de Kant sobre o Iluminismo, mas para a obra de Baudelaire, a partir da qual esboça o quadro ético da inteligência moderna, o filósofo avança quatro traços do ethos da nossa modernidade, um deles sendo a "atitude-limite", que ele define assim:

no Editora, 1998, p. 257.

14. Carta de 7 de julho de 1977. In: CESAR, Ana Cristina. Correspondência incompleta. Rio de Janeiro: Aeroplano; São Paulo: Instituto Moreira Salles, 1999, p. 152.

15. Cf. Carta a Maria Cecilia Fonseca de 29 de junho de 1977. In: Correspondência incompleta, op. cit., p. 149. 
Não se trata de uma postura de rejeição. Deve-se fugir da alternativa do fora e do dentro; precisa estar nas fronteiras. ${ }^{16}$

Estar nas fronteiras, não numa postura do contra, mas analisando e pensando que fronteiras são essas, quais são as suas necessidades.

A crítica é decerto a análise dos limites e da reflexão sobre eles. Mas se a questão kantiana era saber que limites o conhecimento deve renunciar a ultrapassar, parece-me que a questão crítica, hoje, deve se inverter em questão positiva: no que nos é dado como universal, necessário, obrigatório, qual a parte do que é singular, contingente e devido a imposições arbitrárias. Trata-se, em suma, de transformar a crítica exercitada na forma da limitação necessária em uma crítica prática na forma do possível ultrapassar. ${ }^{17}$

Ou seja, o papel crítico do intelectual ou do artista moderno não é transcendental, mas prático. Ele não busca realizar as condições de uma metafísica convertida hoje em ciência, cognição absoluta, mas trata de levar o mais longe possível "o trabalho indefinido da liberdade", isto é, pensar o que dos limites que se apresentam a nós é necessário e o que não é indispensável, o que limita sem fundamentos a constituição de nós mesmos em sujeitos autônomos.

Da mesma forma, portanto, a questão da autonomia do texto literário traz consigo uma reflexão heurística relativa às condições de produção de conhecimento hoje, condições e capacidades relativas, tecendo a análise das condições de liberdade do nosso ser histórico, e certo ceticismo da crítica permanente, irrequieta, justamente porque somos históricos. A pequena vantagem da literatura ou, melhor dizendo, de uma concepção da literatura que está justamente tentando repensar Ana Cristina Cesar é saber que, como escrevia Michel Serres em 1974, no terceiro volume de seu Hermes,

16. "Il ne s'agit pas d'un comportement de rejet. On doit échapper à l'alternative du dehors et du dedans; il faut être aux frontières". In: Dits et écrits, op. cit., p. 1393.

17. "La critique, ceest bien lanalyse des limites et la réflexion sur elles. Mais si la question kantienne était de savoir quelles limites la connaissance doit renoncer à franchir, il me semble que la question critique, aujourd'hui, doit être retournée en question positive: dans ce qui nous est donné comme universel, nécessaire, obligatoire, quelle est la part de ce qui est singulier, contingent et dù à des contraintes arbitraires. Il sagit en somme de transformer la critique exercée dans la forme de la limitation nécessaire en une critique pratique dans la forme du franchissement possible", id. 
justamente dedicado à tradução: não há saber sem ilusão, os mitos e os sonhos estão repletos de saberes assim como os saberes estão cheios de sonhos e ilusões.

Um saber sem ilusão é uma ilusão toda pura. Em que se perde tudo, e o saber. [...] não há mito puro a não ser o saber puro de qualquer mito. ${ }^{18}$

Será que o maldito da revista Extra endossava, ao contrário, uma confiança demasiadamente crédula na capacidade de a literatura "desvendar o real" e, portanto, produzir saberes e verdades sobre a realidade brasileira, uma literatura "documento, reportagem"? Levando em conta a magnífica elaboração poética dos contos de João Antônio, muito longe dessa prosa meramente documental, temos as nossas dúvidas.

Michel Riaudel é professor do Departamento de Estudos Portugueses e Brasileiros da Universidade de Poitiers (França). Sua pesquisa volta-se para a literatura brasileira e as circulações literárias entre Brasil e França. Tradutor de Ana Cristina Cesar, Modesto Carone, José Almino, Milton Hatoum, entre outros.

18. "Un savoir sans illusion est une illusion toute pure. Où lon perd tout, et le savoir. [...] il n'y a de mythe pur que le savoir pur de tout mythe". In: SERREs, Michel. Hermès III. La traduction. Paris: Ed. de Minuit, 1974, p. 259. 